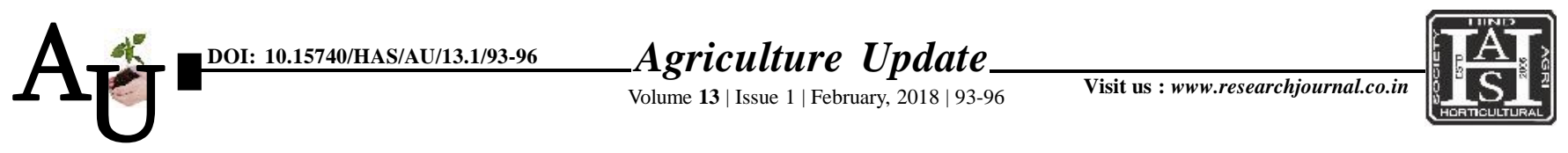

— e ISSN-0976-6847

\title{
Rевенст автісі: Morphological characters of different regions of cowpea (Vigna ungiculata L.)
}

\section{J. Naga Lakshmi and A. Srujana}

Article Chronicle : Received :

06.12.2017;

Revised :

07.01.2018;

Accepted :

23.01.2018

Key Words :

Legume, Asymmetrical, Trifoliate, Drought, Poly ethylene glycol

Author for correspondence :

J. Naga Lakshmi

Department of Botany, Osmania University, Hyderabad (Telangana) India

Email : jakkula. nagalaxmi@gmail.com

See end of the article for authors' affiliations
SUMMARY : The cowpea, Vigna unguiculata (L.) WALP is an important grain legume crop in tropical and sub-tropical areas. Cowpea exhibits a considerable variation in leaf shape. Cowpea leaves are compound, having two asymmetrical side leaflets and one central terminal leaflet which is symmetrical. Typically, the central leaflet of the trifoliate is used in classifying the leaf shape due to variability of the side leaflets. In the present work morphological characters of all the five cultivars are almost similar without much deviation. The average values of all the parameters studied did not reveal the differences among the cultivars. PEG induced drought tolerance in the cultivars indicated the differential sensitivity among the cultivars. The growth parameters like root length, shoot height, leaf length, leaf area etc., clearly differentiated the cultivars for their sensitivity to induced drought by PEG. The cultivar Gangothri is more resistant and Pusakomal is more sensitive to induced drought with PEG among five cowpea cultivars from Telangana.

How to cite this article : Lakshmi, J. Naga and Srujana, A. (2018). Morphological characters of different regions of cowpea (Vigna ungiculata L.). Agric. Update, 13(1): 93-96; DOI : 10.15740/HAS/AU/13.1/93-96. 